\title{
Frames de la religión en editoriales de cuatro periódicos españoles (2009-2010)
}

\author{
Framing religion in the editorials of four Spanish newspapers \\ (2009-2010)
}

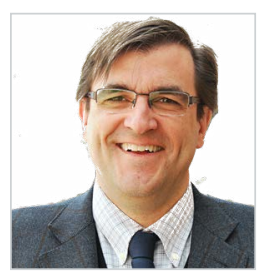

Ricardo-María Jiménez-Yáñez. Doctor en Lingüística por la Universidad de Navarra, profesor asociado de la Universitat Internacional de Catalunya (UICbarcelona). Está acreditado como profesor contratado-doctor (número PCD: 2017-755). Ha sido investigador visitante del CASS (Lancaster University), de la Universidad de Navarra, de la University of Manchester y de la University College of Dublin. Sus intereses incluyen las áreas de análisis crítico del discurso, el estudio del framing en los textos periodísticos, la Lingüística de Corpus y el lenguaje jurídico. Ha escrito el libro Escribir bien es de justicia (2. a edición) en Thomson-Reuters Aranzadi.

Universitat Internacional de Catalunya, España

rmiimenez@uic.es

ORCID: 0000-0002-8065-1289

Recibido: 21/03/2018 - Aceptado: 24/05/2018

\section{Resumen:}

En este artículo se analizan los elementos y las funciones de frame y los máster frames presentes en dos combinaciones de palabras relacionadas con las religiones ("Benedicto XVI" y "velo integral"), de un corpus de editoriales de cuatro periódicos españoles (2009-2010), para investigar cómo se posicionan ideológicamente los periódicos a través de esos textos sobre la representación de la religión en la vida pública. Con un espíritu interdisciplinar, en este trabajo se une metodológicamente el enfoque de framing (Entman), que es más propio del ámbito de la comunicación, con algunas técnicas de la Lingüística de Corpus. Al representar la religión católica, los editoriales analizados ofrecen posturas ideológicas radicalmente diferentes, con una polarización más marcada entre El País y $A B C$, y un enfoque menos partidario, incluso a veces más difuso, en La Vanguardia y El Periódico. En cambio, en la representación del uso del velo y, por extensión, de aspectos importantes de la religión islámica, en $A B C$ y El País los enfoques aparecen un tanto más imprecisos. Finalmente, aunque el "periodismo pluralista" de La Vanguardia y de El Periódico

\section{Received: 21/03/2018 - Accepted: 24/05/2018}

\section{Abstract:}

The main purpose of this article is to analyse the framing elements of the way newspaper editorials dealt with two terms related to religions ("Benedict XVI" and "full headscarf"), using a corpus of editorials published in 2009 and 2010 by four Spanish newspapers, with a view to identifying the ideological framework adopted by these newspapers as they dealt with the theme of religion in the public square. Adopting an interdisciplinary approach, the methodology makes use of the framing approach (Entman), which is used mainly in communication, with that of Corpus Linguistics. The result shows a noticeable correlation between the ideological framework of the newspapers and the arguments put forward in their respective editorials. The application of framing also helps to reveal the particular slant of the newspapers in question. The outcome proves the effectiveness of using Corpus Linguistics techniques in analysing editorials in the Spanish press. Also, when focussing on the Catholic religion, the editorials analysed show radically different ideological positions, with a more noticeable polarisation between $\mathrm{El}$ País and $\mathrm{ABC}$, and a less partisan and clear-cut approach between La Vanguardia and El Periódico. On

Cómo citar este artículo:

Jiménez-Yáñez, R. M. (2018). Frames de la religión en editoriales de cuatro periódicos españoles (2009-2010). Doxa Comunicación, 26, 145-168. 
ofrece una postura ideológica difusa sobre el uso del velo, se han observado matices distintos en el tratamiento de esta prenda por parte de estos dos periódicos.

\section{Palabras clave:}

Framing; editorial; religión católica; religión islámica; Lingüística de Corpus; EDAC. the other hand, when dealing with the issue of the headscarf and, by extension, with the Islamic religion, the difference in the approaches adopted by $\mathrm{ABC}$ and $\mathrm{El}$ País are less noticeable. And rather interestingly, the use of framing shows up some additional approaches in relation the headscarf in both La Vanguardia and El Periódico which are not to be found in the other two newspapers.

\section{Keywords:}

Framing; editorial; Catholic religion; Islam; Corpus Linguistics, CADS.

\section{Introducción}

En el mes de abril del 2010, la joven de 16 años Najwa Malha, alumna del colegio Camilo José Cela de Pozuelo (Madrid), asistía a su centro tocada con un hiyab (velo islámico que solo deja al descubierto el óvalo de la cara). La directiva del centro prohibió el uso de esa clase de velo, ya que la disciplina del colegio impedía a los alumnos cubrirse la cabeza con cualquier prenda. Por otro lado, en el mes de octubre de ese mismo año, en pleno escándalo por los casos de pederastia cometidos por miembros de la iglesia católica, el papa Benedicto XVI realizó su primer viaje oficial al Reino Unido.

Los dos hechos mencionados y próximos en el tiempo, que desataron una intensa controversia, mostraron una relación más o menos relacionada con la percepción de dos religiones (el cristianismo católico y el islam) en el espacio público. En este mismo sentido, llama la atención el alto número de temas polémicos relacionados con la religión que se abordan habitualmente en la prensa española. En España, la “cuestión religiosa” (las relaciones Iglesia-Estado, por ejemplo) ha sido el conflicto más característico de los siglos XIX y XX (Cárcel, 2002: 8). Asimismo, la acusación de comportamientos discriminatorios por motivos de religión -además de por raza, etnia, cultura y género- está a la orden del día (Bañón, 2002: 71), y esos hechos se suelen reflejar en los medios de comunicación. Y no solo sucede en España, este extremo se ha comprobado ya empíricamente, por ejemplo, en el análisis de la prensa británica: “Conflicts and controversies between defenders of Christianity, secularists and adherents of religious minorities have become more visible in public discourse, including media" (Knott, Poole and Taira, 2013: 38), y las evidencias sugieren que estas controversias son de alcance internacional (Woodhead, 2012). Por lo tanto, cuando nos centramos en la representación de las religiones en la prensa, nos encontramos ante un tema de indiscutible relevancia en el discurso público actual.

De todas formas, cabrá tener en cuenta, en las conclusiones, si el estudio contrapuesto de esos dos hechos, radicalmente distintos en protagonismo e influencia, distorsiona el posicionamiento ideológico de los editoriales.

El objetivo central del presente artículo es desarrollar un análisis de los frames que conforman la representación de la religión, centrada en los dos hechos mencionados, en los editoriales de los cuatro periódicos españoles: dos editados en Madrid (El País y ABC) y otros dos, en Barcelona (La Vanguardia y El Periódico); el motivo de la elección de esos periódicos se ofrece en el epígrafe 2.3, al tratar del corpus de editoriales. Este estudio combina el enfoque del framing con técnicas de la Lingüística de Corpus (en adelante LC). Se ha elegido el texto editorial por su relevancia en la comunicación de la ideología del periódico. 


\section{Enfoques, metodología y corpus}

\subsection{Enfoques}

Gregory Bateson empleó por primera vez el término frame en el año 1954, dentro del campo de la psicología. En esta área y en la sociología se concibieron las primeras aproximaciones metodológicas. También se ha estudiado en la lingüística cognitiva. Gracias a Gaye Tuchman, que introdujo su conocida metáfora de la noticia como una ventana desde la que se contemplan los acontecimientos, el enfoque del framing dio el salto al estudio del Periodismo. Posteriormente, dentro de los estudios de comunicación, sobresale la definición de Entman, cuya concepción se aplica en este artículo:

To frame is to select some aspects of a perceived reality and make them more salient in a communicating text, in such a way as to promote a particular problem definition, causal interpretation, moral evaluation and/or treatment recommendation for the item described (Entman, 1993: 52).

Aunque sea brevemente, cabe señalar que Teresa Sádaba (2001) afirma que en los últimos veinte años del siglo XX (19802000) el framing ocupaba un lugar destacado en los estudios de comunicación. Se puede mantener esa afirmación una decena de años después, como lo corrobora el estudio de Borah (2011) que analizó 93 revistas académicas de los años 1997 a 2007. Por otro lado, los artículos de Miguel Vicente Mariño y Manuel López Rabadán (2009) y de Ardèvol-Abreu (2015) permiten conocer el avance y el desarrollo del framing en nuestro país.

De vuelta a la investigación que nos ocupa, a continuación, se tratará de otros conceptos que se emplearán en el análisis de este estudio. Kuypers define "tema" como el objeto de debate o aquello que es el sujeto del pensamiento expresado (2010: 302). Se entiende por "tema problemático" un asunto que crea debate social y resulta conflictivo.

Por otro lado, se atiende a los cuatro elementos interrelacionados que Entman denomina funciones de frame (definición particular de un tema o cuestión, interpretación causal, valoración moral y recomendaciones para el tratamiento del asunto que se describe). Además, en este estudio se tiene en cuenta el concepto de Entman según el cual los frames configuran una narrativa que destaca las conexiones entre los elementos seleccionados de la realidad para promover una interpretación.

Para resolver el grado de organización, Entman (1993: 56) emplea el término framework unificante. Ejemplos de ese término son "Guerra contra el terror" o "Guerra fría" (cold war). Por su parte, en la aportación de Kuypers (2012) se señala que, tanto en el discurso político como en el mediático, pueden existir master frames. Este concepto se refiere a un frame compuesto de distintos temas que, a la vez, cada uno de ellos tiene su propia interpretación, su propio frame. El master frame funciona como un paraguas bajo el cual se encuentra el resto del debate referido al mismo tema (Azpíroz, 2012).

Como se ha anunciado, en este estudio se aplican algunas técnicas de la LC, que es un enfoque metodológico (McEnery \&Wilson, 1996), no una rama de la Lingüística, constituido por un conjunto de principios metodológicos para estudiar cualquier dominio lingüístico, y que se caracteriza por "brindar sustento a la investigación de la lengua en uso a partir de corpus lingüísticos con sustrato en tecnología computacional” (Parodi, 2008: 95). Cabe señalar que una contribución fundamental de la LC es el decidido enfoque empírico que estas técnicas aportan al focalizar datos observables a modo de evidencia científica y que se almacenan como corpus electrónicos (Parodi, 2008: 95). Este enfoque metodológico se 
enmarca en los "Estudios del Discurso Asistido por Corpus" (en adelante, EDAC) (Baker y otros, 2011; Partington, 2017; Jiménez-Yáñez, 2017).

Los estudios de framing en comunicación periodística suelen emplear como metodología el análisis de contenidos. En cambio, la novedad del estudio que nos ocupa radica en que se combinan los métodos de la LC con el enfoque del framing, y que se centra en periódicos españoles. Cabe destacar que uno de los primeros estudios que aplica técnicas de LC y el análisis de frames es el de Touri y Koteyko (2014). Las autoras pretenden demostrar la contribución de las técnicas de LC al análisis de frames en noticias de la prensa inglesa sobre la crisis financiera de Grecia. Por su parte, el estudio de Crenshaw (2014) también permite observar cómo la sinergia entre el framing y la LC contribuye a estudiar los debates sociales presentes en la prensa. Asimismo, Molloy (2015) examina la frecuencia de las palabras clave y aplica los enfoques del framing y el de la agenda-setting, al estudiar la cobertura del grupo terrorista IRA en 1996 en cinco periódicos.

Por último, en este trabajo se valora también qué propuestas de modelos de periodismo resultarán útiles para ubicar los cuatro diarios.

\subsection{Metodología}

Para analizar los hechos de forma más sistemática en los editoriales, se identificó el tema problemático o el tema y los elementos de frame relacionados con las combinaciones frecuentes de palabras de los editoriales, que están vinculados con los debates sociales que suscita la representación de la religión en los editoriales de prensa. Después, se leyeron de nuevo los editoriales en que aparecen las combinaciones frecuentes de palabras relacionadas para identificar los posibles elementos de los frames que aparecen en estos textos. Como es sabido, los periodistas no siempre manejan frames completos en el sentido definido por Entman (1993).

En los textos mediáticos más bien se hace alusión a los aspectos de cada tema que son relevantes en el momento actual, o a los aspectos que son importantes para el escritor, sin presentar un análisis completo. Por esta razón, se ha optado por identificar las ideas sencillas o framing elements que aparecen en cada caso y realizar un análisis preliminar de los temas que destacan en cada periódico, siguiendo a Breeze (2013) en su estudio de los símbolos religiosos en los discursos de los medios británicos.

A continuación, se buscaron las concordancias (esto es, la observación de la palabra en su contexto) de cada combinación frecuente de palabras. Una vez leídas las concordancias de esa combinación, se empezaron a identificar qué framing elements ofrecían o qué frames completos y cuál era el posible tema problemático o tema planteado. Después, se acudió al párrafo de cada combinación frecuente, accesible en SketchEngine desde la línea de la concordancia, con el propósito de establecer lo mismo que en las concordancias.

\subsection{Corpus de editoriales}

El corpus recabado corresponde a los editoriales de los años 2009 y 2010 de cuatro periódicos españoles. Me dispongo a explicar por qué se eligieron esos periódicos. Por un lado, los textos editoriales de El País y el del año 2010 de $A B C$ estaban disponibles en el marco del grupo de investigación GradUN (Grupo de Análisis del Discurso de la Universidad de Nava- 
rra), y habían sido incluidos en el programa SketchEngine por un investigador del mencionado grupo, como parte de un corpus de editoriales amplio que cubre el periodo de los años 2005 a 2010. Por otro lado, el autor de este trabajo aportó los editoriales de los otros dos periódicos -El Periódico y La Vanguardia-, correspondientes a los mismos años y los editoriales de $A B C$ del año 2009. A partir del corpus de los editoriales de $A B C$ y El País, pareció interesante crear otros corpus de editoriales de periódicos de otras comunidades, en especial de la comunidad catalana que conoce de cerca el autor de este estudio. De esta forma, se podrían descubrir los diferentes posicionamientos ideológicos de dos periódicos de Madrid y dos de Barcelona.

Se presenta el corpus general de editoriales que se compone de 2.692,837 palabras (cf. Tabla 1):

Tabla 1. Corpus general de editoriales

\begin{tabular}{|l|c|c|}
\hline \multicolumn{1}{|c|}{ Periódicos } & Años & Palabras \\
\hline ABC & $2009-2010$ & 734,659 \\
\hline El País & $2009-2010$ & 778,584 \\
\hline El Periódico & $2009-2010$ & 522,943 \\
\hline La Vanguardia & $2009-2010$ & 656,651 \\
\hline & & $2.692,837$ \\
\hline
\end{tabular}

Fuente: elaboración propia

A partir de ese corpus general se creó uno centrado en la temática de la religión. Para elaborarlo se han empleado las herramientas del programa de LC SketchEngine que ofrecen un abanico de posibilidades para analizar textos periodísticos. Para seleccionar los textos relacionados con la representación de la religión, se extrajo una lista de palabras clave, obtenidas al comparar el corpus de cada periódico con el corpus de referencia esTenTen11 (Eu + Am, Freeling, Lempos, sample) de $11.173,609,480$ palabras.

De esa lista de palabras clave, se seleccionaron las referidas a actores y acciones religiosas (cf. Tablas 2, 3, 4 y 5):

Tabla 2. Palabras clave de los editoriales $A B C$ (2009-2010).

\begin{tabular}{|c|}
\hline teocrático \\
\hline nasciturus \\
\hline laicismo \\
\hline aborto \\
\hline laicista \\
\hline abortista \\
\hline crucifijos \\
\hline Fuente: elaboración propia
\end{tabular}


Tabla 3. Palabras clave de los editoriales El País (2009-2010).

$$
\begin{array}{|c|}
\hline \text { abortar } \\
\hline \text { Ratzinger } \\
\hline \text { crucifijo } \\
\hline \text { Rouco } \\
\hline \text { teocracia } \\
\hline \text { confesional } \\
\hline \text { vaticana } \\
\hline \\
\text { Fuente: elaboración propia }
\end{array}
$$

Tabla 4. Palabras clave de los editoriales El Periódico (2009-2010).

\begin{tabular}{|c|}
\hline islam \\
\hline prédica \\
\hline pederastia \\
\hline Ratzinger \\
\hline teocracia \\
\hline abortar \\
\hline vaticana \\
\hline
\end{tabular}

Fuente: elaboración propia

Tabla 5. Palabras clave de los editoriales La Vanguardia (2009-2010).

\begin{tabular}{|c|}
\hline islam \\
\hline niqab \\
\hline teocrático \\
\hline burka \\
\hline pontífice \\
\hline Rouco \\
\hline hiyab \\
\hline
\end{tabular}

Fuente: elaboración propia

Posteriormente, se seleccionaron manualmente los textos en los que aparecían esas palabras clave y con ellos se formó el corpus temático de los editoriales de cada uno de los cuatro periódicos, que se compone de 155,598 palabras (cf. Tabla 6): 
Tabla 6. Palabras de todos los editoriales del corpus temático.

\begin{tabular}{|c|c|}
\hline Rel_ELPE 20092010 & 29,202 de 155,598 palabras \\
\hline Rel_PAIS 20092010 & 48,543 de 155,598 palabras \\
\hline Rel_LV 20092010 & 30,004 de 155,598 palabras \\
\hline Rel_ABC 20092010 & 46,964 de 155,598 palabras \\
\hline Todos los editoriales del corpus temático & 155,598 palabras \\
\hline
\end{tabular}

Fuente: elaboración propia

En el corpus temático se exploraron los keywords con la herramienta de wordsketch, que identifica las combinaciones más frecuentes de cada palabra. Después, se optó por un estudio de las combinaciones frecuentes de las palabras que tienen una clara carga significativa en el ámbito de la representación de la religión en la vida pública.

Para realizar este análisis, primero se realizó una búsqueda de las combinaciones frecuentes de palabras ( $n$-grams) usando la función wordlist, y luego se seleccionaron las combinaciones frecuentes que tenían un significado relevante para el tema objeto de estudio. En la Tabla 7 se presentan las primeras veinticinco combinaciones frecuentes de palabras del corpus temático de los cuatro periódicos (cf. Tabla 7):

Tabla 7. Combinaciones frecuentes de palabras de los cuatro periódicos.

\begin{tabular}{|l|l|}
\hline Combinaciones frecuentes de palabras & frec./mill. \\
\hline Benedicto XVI & 9,6 \\
\hline iglesia católica & 5,7 \\
\hline ley del aborto & 4,3 \\
\hline Rodríguez Zapatero & 3,4 \\
\hline libertad religiosa & 3,2 \\
\hline sociedad española & 3,2 \\
\hline aborto libre & 3,1 \\
\hline crisis económica & 3,1 \\
\hline Santa Sede & 2,8 \\
\hline Tribunal constitucional & 2,8 \\
\hline reforma de la ley & 2,6 \\
\hline conferencia episcopal & 2,6 \\
\hline poderes públicos & 2,5 \\
\hline objeción de conciencia & 2,5 \\
\hline Juan Pablo II & 2,5 \\
\hline vida humana & 2,5 \\
\hline
\end{tabular}


Frames de la religión en editoriales de cuatro periódicos españoles (2009-2010)

\begin{tabular}{|l|l|}
\hline Al Qaeda & 2,4 \\
\hline jerarquía católica & 2,4 \\
\hline opinión pública & 2,3 \\
\hline Bibiana Aído & 2,3 \\
\hline Barack Obama & 2,3 \\
\hline interrupción voluntaria & 2,3 \\
\hline Partido Popular & 2,3 \\
\hline velo integral & 2,2 \\
\hline abusos sexuales & 2,2 \\
\hline
\end{tabular}

Fuente: elaboración propia

El número de combinaciones frecuentes de palabras de cada corpus temático oscila entre 25 y 49 . Se optó por elegir la primera combinación ("Benedicto XVI") y otra relacionada con la religión islámica ("velo integral”). El siguiente paso fue establecer qué “temas” se plantean en torno a las combinaciones frecuentes más destacadas.

\section{Resultados}

\subsection{Resultados de los frames sobre el papa Benedicto XVI}

\subsubsection{Valoración de los frames sobre el papa Benedicto XVI en los editoriales de El País}

Se inicia la valoración de los elementos de frame relacionados con las combinaciones frecuentes de palabras seleccionadas. Cabe advertir al lector que por razones de espacio no se presenta un listado exhaustivo de todos los elementos de frame identificados en los editoriales.

En los editoriales de El País los framing elements son casi exclusivamente negativos y, por tanto, el papa se considera un tema problemático porque es un líder espiritual conservador, dogmático y que no actúa con claridad.

Entre los elementos de definición, que se confunden con elementos de causa y elementos de evaluación negativa, sobresalen los siguientes:

- El primero de ellos es que el papa Benedicto XVI forma parte de la jerarquía eclesiástica que pretende reconquistar Europa para las posiciones ultraconservadoras.

- El papa es una persona poderosa con capacidad de mediación en asuntos universales.

- Benedicto XVI no es una persona creíble porque ha de aclarar por qué no resolvió los casos de abusos cuando era prefecto de una congregación, aunque se muestra decidido a acabar con los abusos sexuales.

Como elementos de causa destacan:

- Los papas son conservadores.

- No pueden apartarse de la doctrina tradicional católica. 
Son numerosos los elementos de evaluación negativa que se solapan, en algún caso, con los elementos de definición, como se ha indicado:

- Se comporta con incoherencia pues en su etapa en la Congregación para la Doctrina de la Fe aconsejaba solucionar en secreto los asuntos graves de abusos.

- Muchos ven a Benedicto XVI como una continuidad de Juan Pablo II, papa que arrinconó y desechó las promesas del Concilio Vaticano II.

- Aunque Benedicto XVI parece decidido a acabar con los abusos, lo hace con lentitud.

- En ocasiones, con sus declaraciones ofende gravemente a la sociedad.

- El papa comete errores encadenados que levantan numerosas críticas.

- Por último, el papa se comporta despóticamente como dueño y señor de almas.

Como elementos de evaluación positiva destacan los siguientes:

- En otros editoriales sí sobresale la dureza con la que Benedicto XVI critica el comportamiento del fundador de una institución religiosa que había cometido abusos.

- El papa Benedicto XVI puso empeño en conciliar razón y fe.

- En ocasiones, el papa reconoce sus errores (su torpeza al navegar por internet y la división dentro del catolicismo).

- El papa muestra arrepentimiento por los abusos sexuales cometidos por miembros de la iglesia católica.

- Benedicto XVI es capaz de escribir textos de calidad literaria y emplea un lenguaje claro y contundente al referirse a los problemas económicos y sus remedios, en una encíclica.

No se ofrecen elementos de solución, porque en los editoriales de El País el papa es un tema problemático.

\subsubsection{Valoración de los frames sobre el papa Benedicto XVI en los editoriales de El Periódico}

Se da paso a la valoración de los elementos de frame de la combinación frecuente de palabras "Benedicto XVI" en los editoriales de El Periódico.

El tema problemático latente en los editoriales de este periódico consiste en que el papa es inmovilista y dogmático, pero también es una figura influyente en el mundo para hacer el bien. Por lo tanto, los framing elements presentan cierto grado de contradicción.

Los elementos de definición relacionados con el tema se pueden entender, en algunos casos, como elementos de evaluación positiva y negativa:

- El primer elemento es que el papa tiene prestigio, es influyente y su voz tiene mucha difusión. Es un líder global.

- El papa viaja mucho y mantiene muchos encuentros con la gente. En sus viajes desarrolla una diplomacia equilibrada para solucionar conflictos y busca la paz.

- Los papas tienen sensibilidad por los problemas sociales de nuestro tiempo. 
Se mencionan los elementos de causa sobre el tema:

- El papa es dogmático, inmovilista y tradicional (el peso de la tradición orienta el magisterio de la Iglesia).

- Durante mucho tiempo, el papa Benedicto XVI fue un ejemplo de poder sordo ante los problemas de la humanidad.

Los elementos de evaluación positiva sobre el tema son los que se mencionan a continuación:

- Benedicto XVI presenta un bagaje cultural y moral considerable.

- El papa ha entonado un mea culpa por los casos de pederastia de algunos clérigos y califica esos casos como crímenes.

- Algunos ven en el papa problemas que no corresponden a la Iglesia.

- El papa responde a cuestiones espinosas y cohesiona y da alimenta a los católicos. Benedicto XVI inicia una gira para afianzar el diálogo con los anglicanos. El papa afronta giras complicadas.

- El papa tuvo gestos con las víctimas de los abusos sexuales.

- El papa influye para hacer el bien (liberar presos en Cuba), sin interferir en asuntos de otro estado.

- El papa Benedicto XVI busca restablecer la unidad de la Iglesia.

Los elementos de evaluación negativa son los mencionados a continuación:

- En ocasiones los papas se oponen a la comunidad científica en materia de moral sexual.

- Algunos veían a Ratzinger como un martillo de herejes, otros como una persona que iba a introducir en el papado criterios intelectuales.

- El papa Benedicto XVI no es dialogante ni abierto a la modernidad. A veces interviene con poco tacto ante la opinión pública.

- El papa rompe con lo que acostumbra a hacerse en Navidad (porque adelanta la misa del gallo a las 22.00).

- Se duda si Benedicto XVI pudo hacer más cuando era prefecto de una congregación para atajar el tema problemático de los abusos sexuales.

- Benedicto fracasa en las relaciones con los judíos y los musulmanes.

- Las visitas del papa provocan muestras de rechazo.

- El papa ataca el laicismo.

- La actuación del papa obedece en ocasiones al cálculo político.

Solo se presenta un único elemento de solución:

- Se espera un papa dialogante y abierto moderno.

3.1.3. Valoración de los frames sobre el papa Benedicto XVI en los editoriales de ABC

Una vez acabada la valoración de la combinación frecuente en El Periódico, se analizan los frames en los editoriales de $A B C$. En los editoriales de este periódico no se ofrece un tema problemático relacionado con el papa. En este periódico es un tema que el papa sea una autoridad moral que sigue sus principios y propone soluciones a los problemas del mundo. 
Se ofrecen los siguientes elementos de definición:

- Es la cabeza de la iglesia universal y el líder de millones de católicos.

- Tiene una personalidad excepcional, autoridad moral y es el líder más respetado del mundo.

- Los papas han seguido siempre la misma línea de actuación y no cambian su concepción moral del amor y el valor del sexo como un elemento unido al amor.

- El papa Benedicto es pastor de almas y un intelectual riguroso.

- El romano pontífice denuncia ofensivas contra la iglesia católica.

Se proponen los siguientes elementos de causa del tema:

- El romano pontífice busca la comprensión mutua para hacer frente a los retos de la sociedad actual.

Los elementos de evaluación positiva sobre el tema son los mencionados a continuación:

- Los papas han condenado siempre los totalitarismos de cualquier género.

- En las visitas del papa, las personalidades le ofrecen un amable recibimiento.

- Benedicto XVI condena los abusos sexuales cometidos por católicos y exige transparencia absoluta sobre ellos, a la vez que reconoce que la Iglesia no siempre ha sido vigilante con ese problema.

- La bienvenida espontánea al papa en Glasgow refleja que las gentes de buena fe no se dejan arrastrar por viejas querellas.

- El papa busca superar recelos históricos entre anglicanos y católicos.

- Frente al oportunismo político, el papa demuestra el espíritu de concordia y de justicia.

- El romano pontífice habla claro ante las víctimas de la injusticia y demuestra valentía al no eludir dificultades y enfrentarse a ellas con determinación y firmeza.

- El papa Benedicto XVI emplea palabras serenas y precisas.

- La legitimación del romano pontífice es histórica y espiritual para cientos de millones de personas de todo el mundo y esa historia es la que permite al papa recordar la agresividad laicista de la España de los años treinta.

- La Santa Sede cuida las formas diplomáticas desde hace siglos, porque la diplomacia vaticana atesora mucha experiencia y se ha curtido en destinos difíciles.

- El papa Benedicto XVI no es ultraconservador, sino que sus palabras y escritos ofrecen una visión novedosa para adaptar el mensaje cristiano a la realidad, con mentalidad abierta sin renunciar a unos principios.

- En uno de sus viajes, defiende la función esencial de la mujer.

- Benedicto XVI habla claro y sin rodeos en su condena al antisemitismo.

- En sus viajes el papa actúa con rigor y prudencia. El papa afronta a la luz de la doctrina cristiana las cuestiones más polémicas, sin rodeos ni omisiones. 
No se presentan elementos de evaluación negativa del tema de los editoriales de $A B C$. Las valoraciones negativas recaen en el gobierno de Zapatero y en el laicismo, en los editoriales relacionados con el tema estudiado en este apartado.

En cuanto a los elementos de solución del tema, en realidad son recomendaciones para futuras acciones no del papa sino de la Iglesia y de la sociedad en general:

- La necesidad entre cristianos de superar recelos históricos que no tienen sentido después de tantos siglos.

- Otro elemento es que el mundo tiene que saldar una deuda con millones de personas que carecen de medios elementales para la subsistencia y son objeto de todo tipo de abusos.

- El Santo Padre está decidido a sanear el funcionamiento institucional de la Iglesia.

\subsubsection{Valoración de los frames sobre el papa Benedicto XVI en los editoriales de La Vanguardia}

Para terminar la valoración de la combinación frecuente en los editoriales de los cuatro periódicos, corresponde en esta sección estudiar los editoriales de La Vanguardia. En los editoriales de ese diario en los que se menciona al papa, el tema problemático es que el papa es un líder influyente, valiente y que quiere hacer el bien, pero que le rodea la polémica.

Se presentan los siguientes elementos de definición:

- El romano pontífice es uno de los principales intelectuales europeos, es una autoridad doctrinal, encabeza una realidad humana con mucha experiencia histórica, sus mensajes son escuchados por millones de personas en todo el planeta.

- Es una persona influyente y de impacto.

- Cada papa tiene su propio estilo (un riguroso intelectual alemán sucede a un papa polaco brioso, teatral, valiente, heroico y líder moral en un mundo confuso).

No se proponen elementos de causa del tema.

Los elementos de evaluación positiva del tema son los siguientes:

- Los viajes del romano pontífice son provechosos, abren debates e intentan solucionar problemas históricos (por ejemplo, la primera visita oficial a UK de un papa desde la época de Enrique VIII).

- La Santa Sede da lecciones de modales y demuestra tener en la mente un mapa moderno de Europa.

- El papa alemán hace viajes a lugares complicados y actúa con valentía (visita un país que se enfrentó a Alemania y que hace casi 500 años rompió con la autoridad pontificia romana).

- El papa defiende la función de la religión en la vida pública.

- Por último, el papa proclama la necesidad del diálogo y defiende la paz y la concordia.

Ahora se mencionan los elementos de evaluación negativa:

- El papa Benedicto XVI constata su dificultad de sintonizar con la cultura mediática y comete algunos errores (levantar la excomunión a los lefebvrianos o el fallo de comunicación sobre el preservativo en su visita a África).

- En un discurso el papa provocó un conflicto con el islam. 
- El papa tiene una visión estrictamente moral y religiosa de temas sociales (por ejemplo, al tratar del uso del preservativo en África).

Sobresale un único elemento de solución:

- La necesidad del diálogo.

\subsection{Resultados de los frames del uso del velo integral en las combinaciones frecuentes de palabras}

\subsubsection{Resultados de los frames del uso del velo integral en los editoriales de El País}

En los editoriales de El País, desde el primer editorial se distingue claramente entre el velo integral y el velo que solo cubre la cabeza y el cabello. En esos textos se alude al velo integral con los nombres burka o niqab; se emplea la palabra "velo" o "pañuelo" para mencionar el velo que solo cubre la cabeza.

El tema problemático en los editoriales de El País es que se plantea prohibir el uso del velo integral en los espacios públicos. Cinco de los seis editoriales se centran en el tema del uso de esa prenda; un solo editorial gira en torno al debate del velo o pañuelo. Se considera que el tema problemático se centra en el uso del "velo integral" y que el tema relacionado con el empleo del "velo" o "pañuelo" forma un frame subordinado que se examinará posteriormente.

El elemento de definición es el siguiente:

- El uso del "velo integral" no se exige a un precepto religioso: "el velo integral ni siquiera responde a un precepto religioso, sino a unas tradiciones que solo rigen en algunos países y en ciertos sectores integristas" (PAIS-063)1.

Solo se ha comprobado un elemento de evaluación moral positiva:

- En España el uso del velo es un problema minoritario.

Se han identificado los siguientes elementos de evaluación moral negativa:

- El uso del velo integral impide el desarrollo personal y social de la mujer y la discrimina. Se afirma en el editorial que "resulta evidente lo que el velo integral significa para el desarrollo personal y social de las mujeres que lo portan" (PAIS$062)^{2}$, sin explicitar qué es lo que resulta evidente. En otro editorial se afirma claramente que "el uso del velo integral limita a las mujeres tanto social como personalmente y que, por tanto, cercena sus derechos y las discrimina" (PAIS-063).

- Ante la proximidad de una campaña electoral en España, quizá sea un interés electoralista el que mueva a los partidos políticos que quieren prohibir esa prenda.

- El uso del velo está íntimamente relacionado con la difícil integración de los inmigrantes y con el rechazo que sufren en tiempos de crisis.

No se mencionan elementos de causas que pueden estar implícitas; quizá el desconocimiento que rodea al uso de esta prenda en los países occidentales, el temor a ofender a la población musulmana y el rechazo a los emigrantes musulmanes.

1 (PAÍS-063): editorial de El País, 17-junio-2010, "Los límites del velo integral”.

2 (PAÍS-062): editorial de El País, 5-junio-2010, "Afrontar el debate”. 
En los editoriales de El País se proponen los siguientes elementos de solución:

- Se pide que se reflexione antes de prohibir su uso.

- Se puede rechazar el uso del velo integral por seguridad sin promulgar nuevas leyes.

Hasta aquí se ha analizado la prohibición del velo integral en los espacios públicos. Además, como se ha mencionado anteriormente, el debate en torno al velo constituye un frame subordinado en los editoriales de El País.

Sobre este frame subordinado, se define el tema precisando que el "velo" o "pañuelo" es un símbolo identitario de raíz religiosa con connotaciones de discriminación.

Como elementos de evaluación moral, cabe mencionar que:

- No hay soluciones claras sobre la regulación de su uso.

- Se da una contradicción entre la libertad individual del alumno y el principio de laicidad, y otra contradicción entre ese principio y el derecho a la enseñanza.

- Una política rigorista sobre el uso del velo podría incitar a los fundamentalistas.

- También se señala que no es lo mismo la prohibición de símbolos religiosos en el espacio escolar público, en las aulas, que en la indumentaria particular de los alumnos; sin embargo, no se afirma claramente que unos se deben prohibir y otros no.

Los elementos de solución que se proponen en este frame subordinado son numerosos:

- El sentido común debe guiar la decisión de prohibir el uso.

- Se debe escolarizar a la alumna para que un día acabe renunciando al uso de ese símbolo.

- La nueva ley de libertad religiosa fijará una jerarquía de valores a respetar por todos, sean musulmanes, judíos o católicos.

\subsubsection{Resultados de los frames del uso del velo integral en los editoriales de El Periódico}

Por su parte, en los editoriales de $E l$ Periódico diario, se distingue entre el burka y niqab, términos que designan el "velo integral", y el "velo" que solo cubre la cabeza. Siempre se refiere al velo integral con los nombres burka o niqab; emplea la palabra velo o pañuelo para mencionar el velo que solo cubre la cabeza. Los editoriales de El Periódico no ofrecen de forma tan explícita, como los de El País, la diferencia entre el "velo integral” y el "velo" o "pañuelo", aunque no incurren en ningún error al mencionar una $\mathrm{u}$ otra prenda.

El tema problemático que se plantea en los editoriales de El Periódico es que prohibir el uso del velo puede ser contraproducente. Consideramos que tanto los elementos de frame de la prohibición del uso del "velo integral" como los del uso del "velo" o "pañuelo" no ofrecen frames diferentes en este periódico y se incluyen dentro del mismo grupo de frames. Quizá esa confusión se deba al desconocimiento de esas prendas por parte de los periodistas. De todas formas, sí que se pueden distinguir diferencias en los elementos de evaluación moral. 
El único elemento de definición del tema problemático es que parece que el uso del velo no corresponde al cumplimiento de un precepto religioso.

Los elementos de evaluación moral negativa sobre el uso del velo son:

- El uso del velo supone limitar los derechos de la mujer.

- Su uso parece no corresponder al cumplimiento de un precepto religioso (elemento que es también de definición).

- El verdadero problema de fondo es cómo encajan los emigrantes musulmanes en la sociedad europea (esta idea aparece al comentar la prohibición del velo en Francia y cuando se menciona que ningún musulmán puede sentirse excluido por seguir las reglas de convivencia de nuestra sociedad).

Los elementos de evaluación moral negativa sobre la prohibición del velo son los siguientes:

- Si se prohíbe, se puede provocar que más personas lo usen.

- Resulta distinto prohibir el velo en la escuela que prohibir el burka en la calle.

- Los políticos deben adoptar una postura clara y no se deben dejar llevar por motivos electoralistas.

No se han identificado elementos de causa del tema.

Entre los elementos de solución, que son válidos tanto para el uso del velo como para su prohibición, sobresalen:

- Se debe dialogar sobre el uso del velo y evitar la demagogia.

- Los partidos políticos deben evitar provocar la xenofobia con este debate.

- Todos hemos de ser reconocidos fácilmente en espacios públicos.

- El Estado no debe indicar cómo se ha de vestir en los espacios públicos.

- Se debe buscar una solución global, general y civilizada.

\subsubsection{Resultados de los frames del uso del velo integral en los editoriales de $\mathrm{ABC}$}

Se prosigue con la valoración de los framing elements del uso del "velo integral" en los editoriales del periódico ABC. En los textos de este periódico la combinación "velo integral" se emplea en 1 ocasión y 3 veces la combinación "velo islámico" para designar la prenda que cubre la cabeza y el cabello de la mujer. En $A B C$ el tema problemático es que el uso del velo se debe prohibir, idea que queda de manifiesto ya en el primer editorial que trata del tema.

Se observan los siguientes elementos de la definición que se confunden con los de evaluación moral negativa:

- Es una prenda degradante y discriminatoria para la mujer.

- Es un símbolo del sometimiento de la mujer a la voluntad del marido y de los padres.

- Esta prenda manifiesta un afán de distancia o incluso de rechazo hacia los usos habituales del lugar de acogida.

- El uso del velo no es un problema de libertad religiosa, por eso las creencias religiosas no tienen nada que ver con la exhibición pública de signos cuyo significado resulta cuando menos equívoco.

Como elemento de evaluación moral positiva solo se distingue que: 
- El uso del velo integral empieza a generar un debate en las sociedades occidentales.

Se contemplan diversos elementos de evaluación moral negativa, además de los elementos de definición ya citados. Entre esos elementos de evaluación moral negativa se descubre el propósito de deslegitimizar al PSOE, en unos casos aludiendo claramente a ese partido, en otros refiriéndose a esa organización política veladamente:

- Bajo el pretexto de permitirlo por el multiculturalismo, se oculta una falacia ideológica que dificulta esa integración y, en ciertos casos, como el burka, promueve una discriminación intolerable en el Estado de Derecho.

- El uso del velo pronto será un problema en Europa.

- Liberalizar el uso del velo en los espacios públicos va en contra de la modernización.

- Tolerar el uso del velo se considera una actitud falsamente progresista (quizá la actitud del PSOE) y una muestra del absurdo del laicismo radical intransigente con la iglesia católica, pero comprensivo con el islam.

En los editoriales tampoco no se han identificado elementos de frame relativos a las causas, como sucede en los editoriales de los otros periódicos.

Los elementos de solución que se proponen en los editoriales de $A B C$ son los que se mencionan a continuación:

- Cualquier creencia practicada libremente en el marco de la legalidad merece respeto, pero nadie (tampoco los seguidores del islam) puede exigir privilegios en contra del principio de igualdad y del objetivo de integración plena que debe presidir la política de inmigración en una sociedad desarrollada.

- El artículo 16 de la Constitución reconoce la libertad religiosa, pero siempre dentro del respeto a las reglas básicas en materia de libertad e igualdad que sustentan un sistema político basado en los derechos fundamentales de la persona.

- No se necesita una ley específica que lo prohíba, ya que existen normas ordinarias que impiden a los ciudadanos ocultar completamente su rostro.

\subsubsection{Resultados de los frames del uso del velo integral en los editoriales de La Vanguardia}

Se termina con la valoración de los elementos de frame de la combinación "velo integral" en los editoriales de La Vanguardia. En este periódico el tema problemático es que la prohibición del uso del velo provoca un intenso debate social y que se debe prohibir el uso del "velo integral".

Cabe señalar que los elementos de frame del tema y del tema problemático coinciden. Como elementos de definición se han encontrado los siguientes (uno de ellos también se considera un elemento de evaluación moral negativa):

- El velo es un símbolo religioso.

- El velo integral es una prenda que denigra a la mujer y subvierte la base de nuestra convivencia.

No se han presentan elementos de frame relacionados con las causas del tema.

Como elementos de evaluación moral negativa sobresalen los que mencionamos a continuación:

- El uso y prohibición del velo integral provoca un intenso debate quizá por preocupación social o quizá por tácticas electorales. 
- Se considera claramente distinta la neutralidad religiosa propia de los colegios públicos a que los ciudadanos ejerzan su derecho a exhibir símbolos religiosos.

Entre los elementos de la solución destacan los siguientes:

- Las normativas legales sobre el velo son legítimas, pero exigen más reflexión e interés de las instancias políticas superiores.

- Debemos ser flexibles sobre el uso del velo o pañuelo, pero no debemos aceptar la normalización del velo integral.

- La comunidad musulmana debe reflexionar también sobre la necesidad de modular y adaptar sus costumbres a cada situación.

\section{Conclusiones}

\subsection{Conclusiones sobre el modelo de periodismo}

Damos paso a las conclusiones sobre los modelos de periodismo presentes en los editoriales analizados. Es evidente que los editoriales de los cuatro periódicos ofrecen unas visiones muy diferentes de la figura de Benedicto XVI. Al comparar los elementos de frame de El País y de $A B C$, se observa diferencia entre los numerosos elementos de evaluación negativa sobre el papa en los editoriales de El País, frente a los abundantes elementos de evaluación positiva sobre el papa en los editoriales de $A B C$. Además, parece que se establece un enfrentamiento entre algunos elementos de frame de El País y de $A B C$, que se refleja en la Tabla 8.

Tabla 8. Elementos de frame antagónicos en los editoriales de $E l$ País y en los de $A B C$.

\begin{tabular}{|c|c|}
\hline Elementos de frame de El País & Elementos de frame de $A B C$ \\
\hline El papa es ultraconservador. & $\begin{array}{l}\text { El papa adopta el mensaje cristiano a la realidad, de forma novedosa, con una } \\
\text { mentalidad abierta. }\end{array}$ \\
\hline $\begin{array}{l}\text { El pontífice es retrógrado, dogmático y } \\
\text { conservador. }\end{array}$ & $\begin{array}{l}\text { El pontífice afronta los problemas del mundo contemporáneo en todos los } \\
\text { ámbitos, también en el social y el político. }\end{array}$ \\
\hline $\begin{array}{l}\text { El papa comete errores y manipula la ciencia por } \\
\text { razones ideológicas. }\end{array}$ & El papa actúa con rigor y prudencia. \\
\hline $\begin{array}{l}\text { El papa parece un desinteresado mediador en lo } \\
\text { universal. }\end{array}$ & $\begin{array}{l}\text { El papa goza de autoridad y su legitimación es histórica y social para millones de } \\
\text { personas. }\end{array}$ \\
\hline Es una persona poco diplomática. & La Santa Sede cuida la diplomacia desde hace siglos. \\
\hline Pierde ocasiones de lograr la reconciliación. & $\begin{array}{l}\text { Envía mensajes de solidaridad, paz y comprensión desde una perspectiva } \\
\text { cristiana; promueve el factor religioso para lograr la paz; pide solidaridad } \\
\text { efectiva, paz y libertad para los cristianos perseguidos. }\end{array}$ \\
\hline El papa es anticuado en moral sexual. & El papa es coherente con su concepción moral del amor y la sexualidad. \\
\hline $\begin{array}{l}\text { No es creíble, no es claro, no se sabe qué le } \\
\text { mueve y no es coherente. }\end{array}$ & $\begin{array}{l}\text { Proclama con claridad el mensaje cristiano, incompatible con las ideologías } \\
\text { sectarias. }\end{array}$ \\
\hline
\end{tabular}


Frames de la religión en editoriales de cuatro periódicos españoles (2009-2010)

\begin{tabular}{|c|c|}
\hline Se encuentra solo. & La gente de buena fe le sigue, se le recibe amablemente donde va. \\
\hline Quiere imponer su fe. & $\begin{array}{l}\text { El núcleo de su pensamiento es la unidad de razón y fe; ofrece una enseñanza } \\
\text { basada en valores eternos. }\end{array}$ \\
\hline El papa silencia hechos y actúa con estrategias. & Afronta con la doctrina cristiana cuestiones polémicas sin rodeos. \\
\hline Muestra debilidad al actuar. & $\begin{array}{l}\text { Muestra valentía al atajar los casos de abusos; tiene una personalidad } \\
\text { excepcional; condena la falsedad de los ataques indiscriminados a la fe. }\end{array}$ \\
\hline
\end{tabular}

\section{Fuente: elaboración propia}

Para que el análisis sea ajustado se comparan ahora algunos elementos de frame de evaluación negativa sobre el papa en La Vanguardia y los elementos de evaluación negativa en El Periódico (Tabla 9):

Tabla 9. Elementos de frame de evaluación negativa en los editoriales de La Vanguardia y en los de El Periódico.

\begin{tabular}{|c|c|}
\hline Elementos de frame de La Vanguardia & Elementos de frame de El Periódico \\
\hline (No se han identificado). & $\begin{array}{l}\text { En ocasiones se opone a la comunidad científica en materia de moral } \\
\text { sexual. }\end{array}$ \\
\hline El papa es dogmático e inmovilista. & El papa Benedicto XVI no es dialogante. \\
\hline $\begin{array}{l}\text { El papa reconoce su dificultad para sintonizar con la } \\
\text { cultura mediática y comete algunos errores. }\end{array}$ & El papa interviene con poco tacto en la opinión pública. \\
\hline $\begin{array}{l}\text { Algunos que atacan al romano pontífice no hacen lo } \\
\text { mismo con los líderes de otras confesiones religiosas. }\end{array}$ & (No se han identificado). \\
\hline (No se han identificado). & $\begin{array}{l}\text { El papa sigue un camino de regresión en temas que afectan a los } \\
\text { creyentes y a los ciudadanos. }\end{array}$ \\
\hline $\begin{array}{l}\text { El romano pontífice tiene una visión estrictamente moral } \\
\text { y religiosa. }\end{array}$ & (No se han identificado). \\
\hline (No se han identificado). & $\begin{array}{l}\text { El papa provoca perplejidad en un sector de católicos porque es } \\
\text { tradicional en moral y dogma; sin embargo, critica el capitalismo y los } \\
\text { atropellos del fuerte sobre el débil. }\end{array}$ \\
\hline (No se han identificado). & El papa actúa a veces con cálculo político. \\
\hline (No se han identificado). & Aplica la política de silenciar hechos y esperar a que pase el tiempo. \\
\hline (No se han identificado). & El papa critica el capitalismo. \\
\hline (No se han identificado). & El romano pontífice rompe con una tradición de Navidad. \\
\hline $\begin{array}{l}\text { Solo con mala fe se puede acusar a Benedicto XVI de ser } \\
\text { cómplice con los casos de pederastia. }\end{array}$ & $\begin{array}{l}\text { Se duda si pudo hacer más contra los abusos sexuales cuando fue } \\
\text { prefecto. }\end{array}$ \\
\hline En un discurso el papa provocó un conflicto con el islam. & $\begin{array}{l}\text { El papa Benedicto XVI fracasa en las relaciones con los judíos y los } \\
\text { musulmanes. }\end{array}$ \\
\hline
\end{tabular}

Fuente: elaboración propia 
En este caso, se comprueba que varios elementos de frame de evaluación negativa de un periódico no se corresponden con un elemento opuesto del otro. Esa oposición sucede con el elemento de que el papa ataca el laicismo, que se menciona en El Periódico, o con el de que los que atacan al papa no hacen lo mismo con otros líderes religiosos, como se menciona en La Vanguardia.

Llegados a este punto, a partir de los elementos de frame analizados, cabe aludir al modelo de periodismo que caracteriza a estos dos periódicos. En esa línea, algunos estudios -como el de Bartolomé Castro y Rodríguez-Virgili (2012)- apuntan que en la prensa española en algunos ámbitos se sigue practicando lo que definen López-Escobar et al. (2008) como el "periodismo de trincheras": es decir, un estilo de periodismo en que los representantes de los dos bloques principales se enfrentan unos con otros, descartando posibles formas de acercarse.

Respecto a los modelos de periodismo, en mi análisis se constata la presencia del mencionado "periodismo de trincheras" (López-Escobar et al. 2008) en los editoriales sobre Benedicto XVI en El País y ABC: ambos periódicos proponen frames antagónicos, que revelan la existencia de dos formas opuestas de entender la misma realidad. López-Escobar et al. indican que ese modelo de periodismo no es exclusivo de España, pero en este país se manifiesta con fuerza, y la polarización es más clara en los medios impresos y en las emisoras de radio privadas. Al mismo antagonismo citado en el estudio de López-Escobar et al. se alude en el amplio estudio de Contreras (2004) en el que este autor analizó el framing en el discurso de los textos periodísticos sobre la iglesia católica en prensa internacional.

Por otro lado, se percibe una diferencia importante entre los editoriales de El País y $A B C$-representantes de dos posturas ideológicas opuestas-, y los de El Periódico y La Vanguardia. El framing del papa en los editoriales de La Vanguardia (el papa es un líder influyente, valiente y que quiere hacer el bien, pero que le rodea la polémica) es más positivo que el de $E l$ Periódico.

A diferencia del "periodismo de trincheras", presente en los elementos de frame de El País y de $A B C$, en los editoriales de La Vanguardia y de El Periódico los elementos de frame son tanto positivos como negativos. Estos periódicos ofrecen una perspectiva distinta a los dos periódicos de la capital de España, como se percibe claramente en la tabla comparativa anterior (Tabla 9). Si la definición de "periodismo de trincheras" parece válida en el contexto de aquellos periódicos, al de estos últimos (La Vanguardia y El Periódico) se podría emplear la combinación "periodismo pluralista”, que se caracteriza por presentar -entre periódicos del mismo ámbito geográfico- algunos elementos de frame enfrentados entre sí, otros similares y, por último, elementos de frame únicos de cada periódico. El hallazgo anterior apunta a la presencia de una clase de periodismo más parecido al "modelo neoliberal o pluralista” (Rodríguez-Virgili et al. 2014: 67) característico de los países del norte de Europa, en el que en vez de tomar posturas ideológicas claras alineadas con los principales partidos políticos, los periódicos dan voz a una pluralidad de opiniones que reflejan las corrientes de pensamiento presentes en amplios sectores de la sociedad civil, al menos por lo que respecta a la religión.

\subsection{Conclusiones sobre la metodología empleada y el análisis de las combinaciones de palabras}

a) Respecto a la metodología empleada, las conclusiones de este estudio se desprenden de un análisis que ha combinado los enfoques del framing con herramientas del Análisis Crítico del Discurso y las técnicas de la LC, dentro del enfoque 
del EDAC. Se ha confirmado que la combinación de esos enfoques y técnicas permite desvelar las posiciones ideológicas de los editoriales de los periódicos analizados.

b) Sobre el análisis de "Benedicto XVI", destacan las siguientes conclusiones. En los editoriales de El País, se ofrece un master frame coherente porque los elementos de frame muestran una interpretación desarrollada y compuesta de varios frames negativos sobre el papa que es coherente en los editoriales de este periódico. Por su parte, en los editoriales de La Vanguardia son positivos los elementos de definición y también los de evaluación positiva del tema problemático. En los editoriales de este diario el master frame no es completo y coherente, aunque su orientación ideológica, sin dejar de señalar aspectos negativos del papa, es más positiva que la de El País y de El Periódico. El tema problemático en los editoriales de El Periódico consiste en que el papa es una figura influyente en el mundo para hacer el bien, pero su dogmatismo le frena. En los editoriales de El Periódico se combina una visión negativa del papa con una visión positiva. Sobre la figura del papa los editoriales de $A B C$ ofrecen un tema, no un tema problemático. En los editoriales de este periódico el master frame es completo, porque la visión que ofrece es totalmente consistente: todos elementos de frame ofrecen una interpretación desarrollada positiva del papa, que está de acuerdo con la definición de su figura.

c) Del análisis de la combinación "velo integral" se desprenden las siguientes conclusiones. En los editoriales de El País no se presenta un master frame completo y coherente porque se omiten elementos de causa, y se propone a la vez un frame subordinado sobre el velo o pañuelo. En este periódico es muy completa la evaluación que se realiza del tema problemático. Sus editoriales se inclinan por seguir debatiendo para conocer la solución más adecuada. En los editoriales de El País se menciona el interés electoralista que puede promover el debate del uso del velo. Si bien se decanta por la prohibición del "velo integral", el editorialista matiza mucho las distintas soluciones en el caso del velo o pañuelo sobre el que parece que existen muchas más dudas, también puede que se deba al temor a provocar a los fundamentalistas, como se afirma en un editorial. En los estudios de Giró y Jarque (2006 y 2007) sobre prensa escrita e inmigración se concluía que El País se mostraba partidario del uso del velo en la escuela. En cambio, en los editoriales del corpus temático de este estudio no resulta tan claro ese posicionamiento.

Por su parte, en los editoriales de El Periódico tampoco se presenta un master frame coherente y completo porque no se ofrecen elementos de causa, no se explicita claramente la diferencia entre el velo integral y el velo, y la simbología religiosa de la prenda no se mantiene con coherencia, como tampoco el concepto de libertad individual.

El tema problemático patente en los elementos de frame en los editoriales de $A B C$ es la prohibición de cualquier tipo de velo. Además, se menciona con frecuencia el falso progresismo de los que quieren permitir su uso y las falacias que emplean los que defienden el velo y luego defienden la prohibición de los símbolos cristianos en los espacios públicos. Parece que este periódico busque deslegitimizar la actitud del PSOE, al valorar el uso del velo. Como se ha indicado, en algún caso aludiendo claramente a este partido, en otros casos haciéndolo veladamente.

En los editoriales de $A B C$ se emplea en más ocasiones que en los otros tres periódicos el término "velo islámico", quizá para que el lector no se confunda al leer los nombres niqab, burka y hiyab y no saber cuál de ellos se refiere al "velo integral" y cuál al velo o pañuelo que cubre la cabeza y el cabello de la mujer que lo porta. Al contrastar las valoraciones de los editoria- 
les de $A B C$ del corpus temático de 2009-2010 con el estudio de Abella (2007) que estudia editoriales del 2002, se comprueba la estabilidad de este periódico en su línea ideológica sobre el uso de esta prensa.

En los editoriales de La Vanguardia se propone el tema de ser flexibles con el velo o pañuelo que deja la cara al descubierto y el tema problemático de prohibir el uso del "velo integral", aunque no se presentan dos frames diferentes. Se insiste en que los poderes públicos deben tomar cartas en el asunto, no dejarlo en manos de los ayuntamientos. Solo se menciona en un texto que es un símbolo religioso equivalente a llevar una cruz.

Se incide en la necesidad de que los musulmanes se integren, como lo propone El Periódico, ABC y levemente en El País. También se acude al ambiguo sentido común como lugar de referencia para saber por qué se ha de prohibir o no, elemento que también se menciona en los otros periódicos.

A diferencia de lo que se propone en El País de forma muy imprecisa, en La Vanguardia se considera claramente distinta la neutralidad religiosa en los colegios públicos a que un ciudadano ejerza su derecho a exhibir símbolos religiosos. En los editoriales de La Vanguardia se considera el velo, no el "velo integral", como un símbolo religioso. Solamente en los editoriales de La Vanguardia se propone directamente a los musulmanes que reflexionen sobre cómo se adaptan a las costumbres de los países donde viven.

Tampoco se ofrece un master frame coherente y completo en los editoriales de La Vanguardia por no presentarse elementos de causa y porque no se afirma con consistencia si es un símbolo religioso. Respecto a los estudios de Giró y Jarque de textos del año $2002(2006,2007)$ en los que se afirma que La Vanguardia era partidaria del uso del velo en la escuela, se observa también, como se ha mencionado en las conclusiones de los editoriales de El País y El Periódico, un cambio en la posición ideológica. Los editoriales del corpus no se muestran favorables, sino que se propone ser flexibles y se añaden otros matices sobre su prohibición que se han mencionado anteriormente. Se aprecian, pues, matices distintos en los periódicos publicados en Barcelona, al representar el "velo integral" en los editoriales.

Sin embargo, la polarización ideológica de los diarios El País y $A B C$ se difumina bastante en el tratamiento del uso del "velo islámico" -es decir, cuando se alude a la religión musulmana, como se aprecia también en un estudio de Breeze (2013), que explora el discurso, aplicando el enfoque del framing, sobre el uso de los símbolos religiosos en algunos periódicos británicos. Asimismo, en La Vanguardia y El Periódico los frames sobre el velo integral o islámico reflejan una opinión pública poco sólida sobre un tema de debate que está iniciándose y sobre una prenda poco conocida en el mundo occidental, aunque se representan con matices distintos a los dos periódicos publicados en Madrid.

En las valoraciones de la combinación "velo integral" se aprecian distintas inconsistencias sobre el velo integral y el velo como símbolo religioso. Para El País el velo integral no es un símbolo religioso, pero sí lo es el velo. En los editoriales de El Periódico el velo integral y el velo no corresponden a un precepto religioso. Para $A B C$ ni uno ni otro corresponden a las creencias religiosas. Y para La Vanguardia el velo es un símbolo religioso, sin aludir a si el velo integral encierra un simbolismo religioso. Una muestra de la novedad y el desconocimiento que suponen algunos aspectos del islam. Así pues, se confirma la hipótesis que apunta a que la representación de la religión islámica en los editoriales ofrece lagunas por su desconocimiento en Occidente. 
En la introducción del presente estudio se planteaba la cuestión de si el estudio contrapuesto de los dos hechos analizados, radicalmente distintos en protagonismo e influencia, podía distorsionar el posicionamiento ideológico de los editoriales. En opinión del autor, aunque es indiscutible la premisa anterior, en este estudio los resultados confirman, por un lado, el mencionado desconocimiento de la religión islámica en Occidente que se desvela en la inconsistencia de los elementos de frame de los editoriales; aunque la polémica del velo fue de menor entidad informativa respecto a la visita del papa a Inglaterra, provocó un considerable debate en los medios (Llamas, 2013) y ese debate se reflejó en los editoriales de prensa.

\section{Referencias bibliográficas}

Abella Vázquez, C. M. (2007): “La aparición de los discursos sobre el multiculturalismo en España: el debate del velo en la prensa escrita”. Athenea Digital, 11, pp. 83-103.

Ardèvol-Abreu, A. (2015): "Framing o teoría del encuadre en comunicación. Orígenes, desarrollo y panorama actual en España”. Revista Latina de Comunicación Social, 70, pp. 423-450.

Azpíroz, M. L. (2012): Diplomacia pública: El caso de la guerra contra el terror. Barcelona: UOC.

Baker, P., Gabrielatos, C., Khosravinik, M., Krzyanowski, M., McEnery, T. \& Wodak, R. (2011): «iUna sinergia metodológica útil? Combinar análisis crítico del discurso y lingüística de corpus para examinar los discursos de los refugiados y solicitantes de asilo en la prensa británica». Discurso \& Sociedad, vol. 5(2), pp. 376-416.

Bartolomé Castro, M. y Rodríguez-Virgili, J. (2012): “Pugna de frames en el debate político español”. Estudios sobre El Mensaje Periodístico, 18(2), pp. 439-457.

Borah, P. (2011): “Conceptual issues in framing theory: A systematic examination of a decade's literature”. Journal of Communication, 61(2), pp. 246-263.

Breeze, R. (2013): “British media discourses on the wearing of religious symbols”, in Belle, H. Van, Gillaerts, P., Gorp, B. van, Mieroop, D. van de \& Rutten, K. (eds.): Verbal and visual rhetoric in a media world. Leiden: Leiden University Press, pp. 197-211.

Breeze, R. (2014): "Perspectives on North and South. The 2012 financial crisis in Spain seen through two major British newspapers”. Discourse and Communication, 8(3), pp. 241-259.

Cárcel, V. (2002): Historia de la Iglesia en la España contemporánea. Madrid: Palabra.

Contreras, D. (2004): La iglesia católica en la prensa: Periodismo, retórica y pragmática. Pamplona: EUNSA.

Crenshaw, E. (2014): "American and foreign terrorist: an analysis of divergent portrayals in US newspaper coverage”. Critical Studies on Terrorism, vol. 7(3), 363-378.

Entman, R. M. (1993): “Framing: Toward clarification of a fractured paradigm”. Journal of Communication, 43(4), pp. 51-58.

Giró, X. y Jarque, J. M. (2006): “Prensa escrita e inmigración: Estudio sobre la opinión de los diarios sobre la inmigración procedente de fuera de la Unión Europea y sobre la cobertura informativa de conflictos destacados que tienen relación con ella (Octubre 1999-Junio 2002)”. ZER Revista de Estudios de Comunicación, n. o 20, pp. 251-270. 
Giró, X. y Jarque, J. M. (2007): “El discurso editorial sobre inmigración”, en Zapata-Barrero, R. y Van Dijk, T. A. (eds.): Discursos sobre la inmigración en España. Los medios de comunicación, los parlamentos y las administraciones. Barcelona: CIDOB, pp. 17-44.

Jiménez-Yáñez, R.-M. (2017): La representación de la religión en editoriales de cuatro periódicos españoles (2009-2010). Breeze, R. y Olza, I. (dir.). Tesis doctoral. Universidad de Navarra, Pamplona.

Knott, K., Poole, E. \& Taira, T. (2013): “Christianity, Secularism and Religious Diversity in the British Media”, in Gillespie, M., Herbert, D. \& Greenhill, A. (eds.): Social Media and Religious change. Berlin: De Gruyter, pp. 37-58.

Kuypers, J. A. (2010): “Framing Analysis from a Rhetorical Perspective”, in D’Angelo, P. \& Kuypers, J. A.: Doing News Framing Analysis. Empirical and Theoretical Perspectives. New York: Routledge, pp. 286-312.

Kuypers, J. A., Cooper, S. D. \& Althouse, M. T. (2012): “George W. Bush, the American press, and the initial framing of the War on Terror after 9/11”, in Denton, Jr. (ed.): The George W. Bush Presidency: A Rhetorical Perspective. Lanham, MD: Lexington Books.

Llamas Saíz, C. (2013): "Metáfora y discurso: el debate en torno al velo islámico en la prensa española”, in Delbecque, N., Delport, M.-F. y Michaud Maturana, D. (eds.): Du signifiant minimal aux textes. Études de linguistique ibéro-romane. Limoges: Éditions Lambert-Lucas, pp. 207-224.

López-Escobar, E. et al. (2008): “Election News Coverage in Spain: From Franco's Death to the Atocha Massacre”, in Kaid, L. L.: The Handbook of Election News Coverage around the World. New York: Routledge, pp. 175-191.

McEnery, T. \&Wilson, A. (1996): Corpus linguistics. Edinburgh: Edinburgh University Press, reprinted 2005.

Molloy, D. (2015): "Framing the IRA: beyond agenda setting and framing towards a model accounting for audience influence”. Critical Studies on Terrorism, Special Section: Emergent Voices in CTS, pp. 1-13.

Parodi, G. (2008): “Lingüística de Corpus: una introducción al ámbito”. Revista de Lingüística Teórica y Aplicada Concepción (Chile), 46(1), pp. 93-119.

Partington, A (2017): "Varieties of non-obvious meaning in CL and CADS: From 'hindsight post-dictability' to sweet serendipity”. Corpora 12(3), p. 339-367.

Rodríguez-Virgili, J., López-Escobar, E. y Tolsá, A. (2011): “La percepción pública de los políticos, los partidos y la política, y uso de medios de comunicación”. Commucation \& Society, XXIV(2), pp. 7-39.

Rodríguez-Virgili, J., Jandura, O. y Rebolledo de la Calle, M. (2014): “La personalización de la política en la cobertura mediática: una comparación de las campañas electorales en España y Alemania”. Trípodos, 34, pp. 61-79.

Sádaba, T. (2001): “Origen, aplicación y límites de la teoría del encuadre (framing) en comunicación”. Communication \& Society, 14(2), pp. 143-175.

Touri, M. \& Koteyko, N. (2014): “Using corpus linguistic software in the extraction of news frames: towards a dynamic process of frame analysis in journalistic texts”. International Journal of Social Research Methodology, 18(6), pp. 601-616. 
Frames de la religión en editoriales de cuatro periódicos españoles (2009-2010)

Vicente Mariño, M. y López Rabadán, P. (2009): "Resultados actuales de la investigación sobre framing: sólido avance internacional y arranque de la especialidad en España”. ZER Revista de Estudios de Comunicación, n,o 26, pp. 13-34.

Woodhead, L. \& Catto, R. (eds.) (2012): Religion and Change in Modern Britain. London and New York: Routledge.

\section{Reconocimiento y financiación}

Esta investigación se ha realizado con el apoyo del proyecto (Ref. FFI2015-65252-R) "El demos en el imaginario de la nueva política: el debate sobre la voluntad popular en el discurso público en Europa" financiado por MINECO, dentro del grupo de investigación gradUN. 